\title{
FABRICATION OF MICROEMULSION LOADED SUBLINGUAL FILM FOR RAPID ABSORPTION OF FENTANYL CITRATE IN TRANSIENT BREAKTHROUGH PAIN
}

\author{
D. MUNDHEY ${ }^{*}$, N. SAPKAL ${ }^{b}$, A. DAUDa \\ aCentre for Advanced Research and Innovation (CARIn), Zim Laboratories Ltd. B-21/22, MIDC Area, Kalmeshwar 441501 Dist. Nagpur (M. \\ S.), India, bGurunanak College of Pharmacy, Nari, Kamgarnagar, Nagpur (M. S.), India \\ Email: dmundhey1990@gmail.com
}

Received: 10 Jan 2021, Revised and Accepted: 22 Mar 2021

\begin{abstract}
Objective: The present research work aims to develop a microemulsion loaded sublingual film for rapid absorption of fentanyl citrate in transient breakthrough pain.

Methods: The Fentanyl citrate microemulsion loaded sublingual film was prepared using Capmul MCM C8 (oil), tween 20 (surfactant) and propylene glycol (co-surfactant) with different grades of film-forming polymer (HPMC) using a film casting machine. The films were evaluated for in vitro disintegration study, tensile strength, folding endurance, content uniformity, drug content, in vitro dissolution, pH, thickness and weight variation, scanning electron microscopy, ex vivo permeation study, droplet size, polydispersity index, zeta potential, \% moisture content and
\end{abstract} stability study were evaluated.

Results: The optimized film formulation showed desired mechanical properties (tensile strength of $0.291 \mathrm{~kg} / \mathrm{cm}^{2}$ ) and a minimum disintegration time of $20 \mathrm{~s}$. The optimized sublingual film formulation exhibited $43.16 \%$ of FC microemulsion loading. Morphological study showed the absence of drug crystals on the polymeric surface. Permeation studies through goat sublingual mucosa indicated $89 \%$ fentanyl citrate release through fentanyl citrate microemulsion loaded sublingual film, whereas only $40 \%$ fentanyl citrate release was obtained when it was directly added to film without microemulsion strategy.

Conclusion: The present study indicated that extend of permeation of fentanyl citrate when added to the sublingual film in microemulsion form was around 2.225 folds higher than when added directly to film without microemulsion. The present microemulsion embedded film technology could be a promising alternative to conventional drug delivery systems and traditional routes of administration for breakthrough pain management.

Keywords: Fentanyl citrate, Microemulsion, Sublingual film

(C) 2021 The Authors. Published by Innovare Academic Sciences Pvt Ltd. This is an open access article under the CC BY license (https://creativecommons.org/licenses/by/4.0/)

DOI: https://dx.doi.org/10.22159/ijap.2021v13i3.40744. Journal homepage: https://innovareacademics.in/journals/index.php/ijap

\section{INTRODUCTION}

Fentanyl citrate (FC) is a small and potent $\mu$-receptor agonist that is given in low doses $(100-1000 \mu \mathrm{g})$, and lacks the bitter taste associated with some other opioids [1, 2]. FC is known to be effective in the treatment of breakthrough pain which is estimated in more than half of cancer patients [3]. Breakthrough pain in cancer patients ranges from $40 \%$ to $93 \%$, and these patients suffer an average of 4 episodes of breakthrough pain per day $[4,5]$. For the successful treatment of transient breakthrough pain, the analgesic used must be fast-acting and provide immediate pain relief. The low oral bioavailability of FC limits its therapeutic utility due to metabolism by the enzyme CYP3A4 in the gastrointestinal tract as well as first passes hepatic clearance [6-8].

Fentanyl is a highly lipophilic compound (octanol-water partition coefficient at $\mathrm{pH} 7.4$ is $816: 1$ ) having peak analgesic effects within a few minutes of IV administration and a duration of action, after small to moderate doses, of 30 to $60 \mathrm{~min}$ [9]. But parenteral administration of fentanyl is usually unsuitable or inconvenient for the patient for the self-management of breakthrough pain, especially in the home environment. Fentanyl has therefore been formulated for administration by a number of alternative routes including transdermal [10], pulmonary [11, 12], oral [13-15], oral transmucosal [16-19] and intranasal [20-22]. Sublingual administration is noninvasive, and the transmucosal absorption of lipophilic drugs is rapid [23-25]. Sublingual fentanyl appears to be clinically useful, safe and well tolerated by the patients [26] and causes minimal mucosal irritation [19]. Whereas the sublingual route offers good bioavailability (57\%) and which further can be increased by proposed strategy.

Thus currently there is a need for a sublingual film dosage form that provides the desired absorption level of fentanyl. Hence, the objective of the current research work was to develop a fast- dissolving microemulsion (ME) loaded sublingual film of fentanyl citrate for transient breakthrough pain. To achieve this objective, fentanyl citrate in microemulsion form is incorporated into the sublingual film for better sublingual bioavailability.

\section{MATERIALS AND METHODS}

\section{Materials}

Fentanyl citrate USP was purchased from Rusan Pharma Ltd. Works, Ankleshwar, Gujrat. Propylene Glycol was purchased from Shell Chemicals, Singapore. Capmul ${ }^{\circledR}$ MCM C8 (Mono/diglycerides of caprylic acid) was obtained as a gift sample from ABITEC Corporation, Columbus, USA. Monebat ${ }^{\circledR}-20$ (Polyoxyethylene 20 sorbitan monolaurate) was obtained as a gift sample from Mohini Organics Pvt. Ltd. Malad (West), Mumbai.

\section{Methods}

Preparation of fentanyl citrate microemulsion loaded sublingual films

Polymeric ME drug-loaded sublingual film was prepared using film casting machine at $1.5 \mathrm{~V}$ and wet thickness of $0.50 \mathrm{~mm}$ and dimensions of film was set at $20 \times 22.5 \mathrm{~mm}$ and dried immediately. Preparation of FC microemulsion and polymeric solutions used to make are as follows. Weigh each ingredient accurately as described in table 1 to prepare formulations F1 to F3. Initially, FC microemulsion was prepared using Capmul MCM C8 (oil), tween 20 (surfactant) and propylene glycol (co-surfactant) using water titration method [27, 28]. In C2 optimized microemulsion, Smix ratio was 1:1 (table 1). This resulted into the formation of a clear microemulsion and to it calculated quantity of FC was added and sonicated for $30 \mathrm{~min}$. Then alpha-tocopherol acetate and BHA (as an antioxidant), sucralose (sweetener), sunset yellow (color) and orange flavor were added and further sonicated for 20 min to obtain 
solution A. Separately, HPMC E5, HPMC E15 was dissolved in water by continuous stirring and allowed to swell for $60 \mathrm{~min}$ to obtain solution B.

Then, FC loaded ME i.e. solution A was mixed with hydrated polymeric solution i.e. solution B with continuous stirring on mechanical stirrer (Remi motors, Remi Electrotechnik Ltd., Vasai, Mumbai, India) for nearly $40 \mathrm{~min}$ to obtain a homogeneous mixture i.e. solution C. Finally; solution $\mathrm{C}$ was cast on the film casting machine and allowed to dry at $50{ }^{\circ} \mathrm{C}$ for $40 \mathrm{~min}$. On removal from the release liner, the film was checked for any imperfections before being cut into $20 \times 20 \mathrm{~mm}$ squares [29].

Table 1: Composition of C2 ME microemulsion loaded sublingual films on film casting machine

\begin{tabular}{|c|c|c|c|c|}
\hline \multicolumn{2}{|c|}{ Ingredients (\%) } & \multirow{2}{*}{$\begin{array}{l}\text { F1 } \\
-\end{array}$} & \multirow{2}{*}{$\begin{array}{l}\text { F2 } \\
-\end{array}$} & \multirow{2}{*}{$\begin{array}{l}\text { F3 } \\
3.15\end{array}$} \\
\hline Fentan & & & & \\
\hline $\mathrm{C} 2 \mathrm{ME}$ & Capmul MCM C8 & 9.35 & 4.46 & 4.32 \\
\hline & Tween-20 & 24.91 & 11.90 & 11.52 \\
\hline & PG & 12.43 & 5.94 & 5.75 \\
\hline & $\mathrm{H} 2 \mathrm{O}$ in ME & q. s. & q. s. & q. $s$. \\
\hline \multicolumn{2}{|c|}{ HPMC E 5} & - & 51.62 & 50.0 \\
\hline \multicolumn{2}{|c|}{ HPMC E 15} & 48.65 & 23.33 & 22.6 \\
\hline \multicolumn{2}{|c|}{ Sucralose } & 1.62 & 1.29 & 1.25 \\
\hline \multicolumn{2}{|c|}{ Orange flavour } & 1.62 & 1.29 & 1.25 \\
\hline \multicolumn{2}{|c|}{ Sunset yellow color } & 0.05 & 0.02 & 0.02 \\
\hline \multicolumn{2}{|c|}{ Alpha tocopherol acetate } & 0.32 & 0.15 & 0.15 \\
\hline \multicolumn{2}{|c|}{ D. M. water } & q. s. & q. s. & q. s. \\
\hline \multicolumn{2}{|c|}{ Total film weight } & 18.5 & 38.74 & 40.00 \\
\hline
\end{tabular}

\section{Development of plain fentanyl citrate sublingual films}

Plain Fentanyl citrate sublingual films were casted on film casting machine. The purpose of these films was to be used as control for in vitro drug dissolution study and ex vivo drug release study. The formulation code and composition of plain fentanyl citrate sublingual film was given in table 2 . The hydrophilic polymers were dissolved in a fixed quantity of distilled water and kept aside for 60 min for swelling of the polymers. To this polymeric dispersion, the weight quantity of fentanyl citrate was added and stirred continuously on a mechanical stirrer (Remi motors, Remi Electrotechnik Ltd., Vasai, Mumbai, India) for nearly 60 min to obtain a homogeneous mixture. Resulting solution was casted on film casting machine and allowed to dry at $50{ }^{\circ} \mathrm{C}$ for $40 \mathrm{~min}$. On removal from the release liner, the film was checked for any imperfections before being cut into $20 \times 20 \mathrm{~mm}$ squares. Obtained films were used for the comparative release profile of the drug.

Table 2: Composition of plain fentanyl citrate sublingual films

\begin{tabular}{ll}
\hline Ingredients (\%) & FC Films \\
\hline Fentanyl citrate & 4.01 \\
HPMC E5 & 63.75 \\
HPMC E15 & 28.82 \\
Sucralose & 1.59 \\
Orange flavor & 1.59 \\
Sunset yellow colour & 0.03 \\
Alpha tocopherol acetate & 0.19 \\
D. M. water & q. s. \\
\hline
\end{tabular}

\section{Characterization of FC microemulsion loaded sublingual film}

\section{In vitro disintegration study}

In vitro disintegration of film was performed as described. Initially, the film was carefully clamped from both the side and placed in a beaker in such a way that water level should be at half level of the film. The time required to break the film was recorded as disintegration time.

\section{Mechanical characterization}

\section{Tensile strength}

The prepared films were subjected for the determination of mechanical properties using using LINUX Tensile Tester (model TEN MD), LINUX Machine Incorporation, Thane, Maharashtra, India, instrument according to the procedure described as follows [30].
The films of dimensions $30 \times 5 \mathrm{~mm}$ were cut and subjected for the analysis. Film specimens with physical defects were discarded. The films were carefully placed between the two vertical grips of the tester during the test. The movable grip was then driven upward with a speed of $30 \mathrm{mV} / \mathrm{min}$ until the rupture of the film. From the recorded load extension profiles, the tensile strength, percent elongation at break was calculated.

\section{Folding endurance}

The folding endurance was determined by repeatedly folding one film at the same place without breaking [31]. Folding endurance is used to estimate the mechanical property of a film [32].

\section{Content uniformity}

Content uniformity of films was determined with the assay of ten individual films. Each film was transferred to a $20 \mathrm{ml}$ volumetric flask and dissolved and extracted in methanol. Drug extracted in methanol was analyzed using high-performance liquid chromatography (HPLC) method [33]. Briefly, drug analysis was performed Princeton SPHER-100 C18 HPLC column $(250 \mathrm{~mm} \times 4.6 \mathrm{~mm}, 15)$ with the mobile phase consisting of solution A (ammonium acetate solution $11 \mathrm{~g}$ in $100 \mathrm{ml}$ water) and solution B (mixture of methanol, acetonitrile, glacial acetic acid) (400:200:0.6); where mixture of solution $A$ and solution $B$ (400:600) and $\mathrm{pH}$ was adjusted to $6.6 \pm 0.1$ with glacial acetic acid, used as mobile phase at a flow rate of $1.5 \mathrm{ml} / \mathrm{min}$. Sample injection volume was $25 \mu \mathrm{L}$ and FC detection was performed using Shimadzu LC solution software at a wavelength of $230 \mathrm{~nm}$.

\section{Drug content}

Ten films were picked randomly and weighted individually. 10 strips (equivalent to $8 \mathrm{mg}$ fentanyl) was weighed and transferred in 100.0 $\mathrm{ml}$ of volumetric flask. About $60.0 \mathrm{ml}$ of water was added and sonicated for $20 \mathrm{~min}$ with intermediate shaking and volume was made upto $100.0 \mathrm{ml}$ with water. This solution was then filtered through a $0.45 \mu \mathrm{m}$ pore size nylon membrane ( $80 \mathrm{ppm}$ fentanyl) and analyzed using HPLC method [33].

\section{In vitro dissolution}

The in vitro dissolution of the formulations was studied as per the US FDA-recommended dissolution methods [34] in $500 \mathrm{ml} 25 \mathrm{mmol}$ phosphate buffer $\mathrm{pH} 6.4$ at $37.0 \pm 0.5{ }^{\circ} \mathrm{C}$ using the USP Apparatus I (Basket) at $100 \mathrm{rpm}$. At predetermined time intervals for $30 \mathrm{~min}, 10 \mathrm{ml}$ of aliquots was withdrawn and replaced with an equal volume of fresh phosphate buffer to ensure sink condition. Aliquots were then analyzed using HPLC method as described in "Content uniformity." This in vitro dissolution study was performed for optimized formulation C2 ME (F3) (table 1), developed with proposed strategy of FC microemulsion 
incorporated into sublingual film. The release profile of C2 ME (F3) sublingual film was compared with plain fentanyl citrate sublingual film (table 2) in which microemulsion was not added.

\section{Measurement of $\mathrm{pH}$}

The $\mathrm{pH}$ study was carried out by preparing $1.0 \% \mathrm{w} / \mathrm{v}$ solution of film at $25^{\circ} \mathrm{C} \pm 0.5^{\circ} \mathrm{C}$. $\mathrm{pH}$ measurement was done using $\mathrm{pH}$ meter (Contech Instruments Ltd., Navi Mumbai, India). In this method pH probe was placed in contact with $1.0 \% \mathrm{w} / \mathrm{v}$ solution of film and the pH was recorded [35].

\section{Thickness and weight variation}

The thickness of films was measured using a digital micrometer screw gage (Mitutoyo, Microvision Calibration Services, Japan). For each formulation, three randomly selected films cut into $20 \times 20 \mathrm{~mm}$ were used. Thickness was measured at five different points in the films and mean value was expressed [35]. Each film was weighted individually on an analytical balance (Shimadzu, Japan) and average weight calculated [36].

\section{Percent loading of FC ME in sublingual film}

The percent loading of FC ME in sublingual film was determined by calculating the amount of ME (g) added to the total casting solution of hydrated polymers (g). The film has been casted till no more evidence of oiliness was observed on the surface of casting plate after removal of dried sublingual strips. The percent loading of FC $\mathrm{ME}$ in sublingual film was calculated from the following equation:

$$
\begin{aligned}
& \text { Percent loading of FC ME in sublingual film } \\
& =\frac{\text { Amt of FC ME added to casting solution }(\mathrm{g})}{\text { Total weight of casting solution }(\mathrm{g})} 100
\end{aligned}
$$

\section{Scanning electron microscopy (SEM)}

The morphological characteristics of the films were studied using SEM. The purpose of the morphological study was to evaluate the film samples for the presence of any deformities, microemulsion droplets and cracks. The samples were examined in a Phenom G2 Pro/G2 pure, Eindhoven, Netherlands, Scanning electron microscope at an acceleration voltage of $10 \mathrm{kV}$.

\section{Ex vivo permeation study}

The ex vivo sublingual permeation of $\mathrm{FC}$ through the goat sublingual mucosa was performed using a modified Franz glass diffusion cell [37]. Goat sublingual mucosa was obtained from the slaughter house and mounted between the donor and receptor compartments. The developed sublingual film was placed on the smooth surface of mucosa by gentle pressing and the compartments were clamped together. The donor compartment was moistened with $1 \mathrm{ml}$ of distilled water ( $\mathrm{pH} \mathrm{6.2)} \mathrm{and} \mathrm{the} \mathrm{receptor} \mathrm{compartment} \mathrm{was} \mathrm{filled} \mathrm{to}$ touch the membrane with distilled water. The fluid motion in the receptor compartment was maintained by stirring with a magnetic bead at $100 \mathrm{rpm}$ and its temperature was maintained at $(37 \pm 0.2){ }^{\circ} \mathrm{C}$. At predetermined time intervals, a $1 \mathrm{ml}$ sample was withdrawn (replaced with fresh medium) and analyzed using HPLC method [33]. Data analysis was done to calculate steady-state fluxes (Jss).

\section{Droplet size, polydispersity index (PDI) and zeta potential}

Re-dispersion (o/w microemulsion re-dispersed from films) of optimized F3 (FC C2 ME) sublingual film was performed to measure particle size and PDI using dynamic light scattering (DLS) (Malvern Zetasizer ZEN3500, UK) and zeta potential using the nanopartica SZ100 (Horiba Scientific Ltd., Japan). Square films with an area of 4.0 $\mathrm{cm}^{2}$ were placed in $10 \mathrm{ml}$ of de-ionized water. All measurements were performed with a scattering angle of $90^{\circ}$ at $25.0^{\circ} \mathrm{C}$; after diluting the dispersion to an appropriate volume with dispersion medium viscosity $0.894 \mathrm{mPa}$. s. A small-volume disposable zeta cell was used for the measurement of electrophoretic mobility $(\mu \mathrm{m} / \mathrm{s})$ and it is converted to zeta potential by using software with the help of Helmholtz-Smoluchowski equation.

\section{\% Moisture content (Karl Fisher titration method)}

Compact volumetric KF titrator (Metrohm, 915 KF Ti-touch, Swiss made) was used for the determination of water content in the sublingual film. Then film sample of $100.0 \mathrm{mg}$, was added to glass container containing sufficient quantity of KF reagent for complete standardization and analysis of sample. Water content was calculated automatically by the apparatus.

\section{Stability study}

Stability study was performed at room condition and at $40^{\circ} \mathrm{C} / 75 \%$ $\mathrm{RH}$ for $4 \mathrm{w}$. Each strip of optimized batch F3 was packed in three layered laminated aluminium pouch and ten pouches are packed in a carton. After $4 \mathrm{w}$, the films were evaluated for the physical appearance, surface $\mathrm{pH}$ and drug content.

\section{RESULTS AND DISCUSSION}

\section{Optimization of FC microemulsion loaded sublingual film formulation}

In the present study FC microemulsion was incorporated into the sublingual film and for that ME with $S_{\text {mix }}$ ratio of $2: 1$ was selected and quantities of each ME was fixed as per solubility, to incorporate $1.26 \mathrm{mg}$ dose of FC. Polymers with different viscosities such as HPMC E5 and E15 were selected for development of immediate release sublingual film. These trial batches were evaluated for its film forming capacity. In F1 trial batch the amount of HPMC E15 was added to obtain the complete incorporation of microemulsion into the sublingual film. The total film weight obtained for F1 trial batch was $19.0 \mathrm{mg}$; which was not suitable for uniformity of weight on film casting machine. Hence the film weight was required to be increased upto $40.0 \mathrm{mg} /$ film. Hence in further trials F2 and F3, HPMC E5 was added along with HPMC E15 to obtained the required film weight on film casting machine. Optimized trial batch F3 contains $50.0 \%$ of HPMC E5 and 22.6\% of HPMC E15, which was sufficient to completely incorporate $\mathrm{C} 2$ microemulsion into the sublingual film and oiliness was not observed on the surface of the polyethylene base sheet after removal of the sublingual film. Uniformity of weight on film casting machine was obtained for this optimized batch (F3) and also exhibited complete \% loading of C2 ME in F3 sublingual film.

\section{Characterization of FC microemulsion loaded sublingual films}

\section{Physicochemical characteristics of the sublingual film}

The physicochemical properties of the ME-loaded sublingual film formulations are shown in table 3 . A weight variation value $(\mathrm{mg})$ of optimized film was in the range of $41.0-44.0 \mathrm{mg}$. The average thickness of films ranged from 0.125 to $0.130 \mathrm{~mm}$. Thus there was proportional gain in weight of films with that of an increase in the thickness of films. The optimized sublingual film formulation i.e. FC C2 ME sublingual film (F3) showed the value of folding endurance $>20$ (table 3). This value is desirable because it would not allow easy dislocation of the films from the site of application or breaking of film during administration.

The $\mathrm{pH}$ values of optimized films indicate that it will not produce any local irritation upon contact with the sublingual mucosa, as it is in the range of salivary pH (6.0-7.0) [38]. Disintegration time of optimized sublingual film formulation was found to disintegrate in less than $30 \mathrm{sec}$ and has sufficient mechanical strength to bear stress during transport and administration of the films.

Table 3: Physiochemical characteristics of optimized microemulsion loaded Fentanyl citrate sublingual film

\begin{tabular}{ll}
\hline Evaluation parameters & F3 (FC C2 ME) \\
\hline Thickness (mm) & $0.13 \pm 1.02$ \\
Weight (mg) & $42.4 \pm 0.27$ \\
Folding endurance & $23.0 \pm 0.82$ \\
$\mathrm{pH}$ at $25^{\circ} \mathrm{C}$ & $6.8 \pm 0.08$ \\
Tensile strength $\left(\mathrm{kg} / \mathrm{cm}^{2}\right)$ & 0.291 \\
$\%$ Elongation at break (\%) & 2.4 \\
Disintegration time $(\mathrm{sec})$ & $19.64 \pm 0.82$ \\
Microemulsion loading (\%) & 43.16 \\
Drug content (\%) & $105.0 \quad \pm 0.07$ \\
\hline
\end{tabular}

Note: Date given in mean $\pm \mathrm{SD}$, where $\mathrm{n}=3$ 


\section{In vitro dissolution study}

FC C2 ME sublingual film (F3) showed highest drug release of $98 \%$ within $5 \mathrm{~min}$; whereas plain FC sublingual film showed relatively less amount of drug release of $45 \%$ within 5 min (fig. 1.). This exhibited that the proposed strategy of ME incorporated sublingual film reduces the particle size by forming $\mathrm{o} / \mathrm{w}$ type of ME droplets, helps in increasing the surface area and, hence, modulates the drug release with a faster rate as compared to the release rate of plain FC sublingual film.

Key attributing factor for differential dissolution profile of C2 ME incorporated fentanyl citrate sublingual film (F3) was due to higher solubility of fentanyl in co-surfactant i.e. propylene glycol and surfactant i.e. tween 20 present in $\mathrm{S}_{\text {mix }}$ ratio (T-20: PG) of 2:1 in F3.

Hence FC C2 ME sublingual film (F3) was considered as an optimized formulation based on its in vitro dissolution profile and further evaluated for SEM studies, content uniformity, droplet size, PDI, ZP and ex vivo permeation study using goat sublingual mucosa.

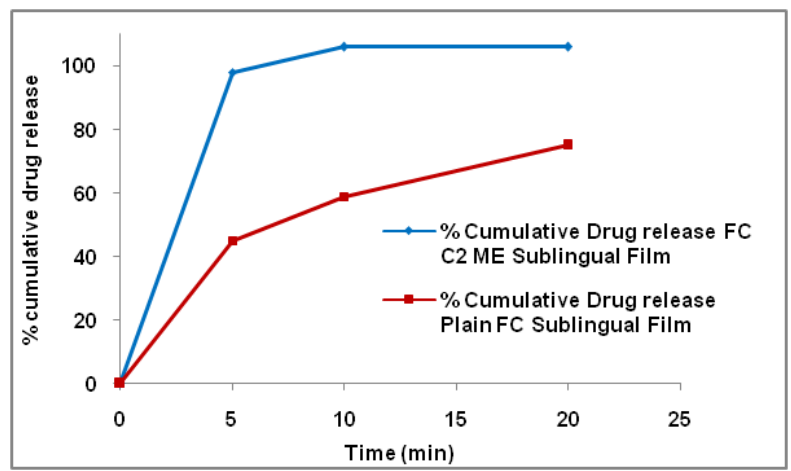

Fig. 1: In vitro release profile of fentanyl citrate through FC C2 ME sublingual film (F3) and plain fentanyl citrate sublingual film

\section{Content uniformity}

The content uniformity of optimized FC C2 ME sublingual film (F3) was found to be within the acceptance criteria. The \% RSD was observed to be less than $2 \%$ which indicates uniformity of content.

\section{Scanning electron microscopy (SEM)}

SEM images of FC C2 ME (F3) and placebo film developed without the addition of microemulsion was shown in fig. 2 and 3. Well dispersed FC microemulsion was obtained in F3, whereas microemulsion droplets were not observed in the placebo films developed without the addition of microemulsion. SEM images of vaccum oven-dried microemulsion incorporated film showed spherical-shaped nanoparticles embedded in the polymeric matrix.

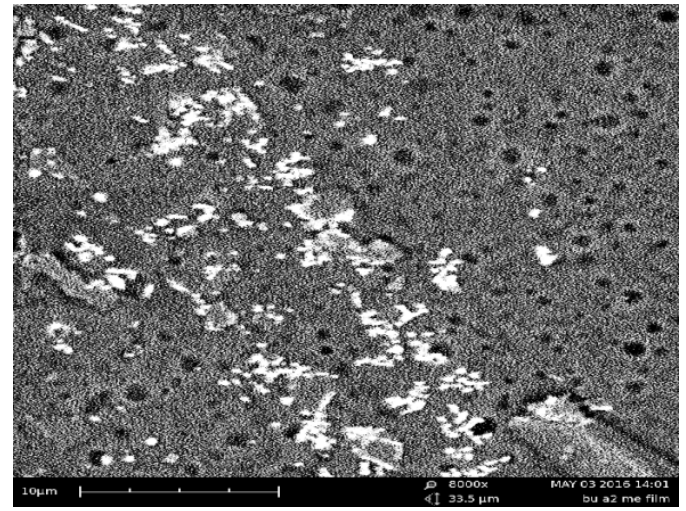

Fig. 2: Scanning electron microphotograph of fentanyl citrate microemulsion loaded sublingual film FC C2 ME (F3)

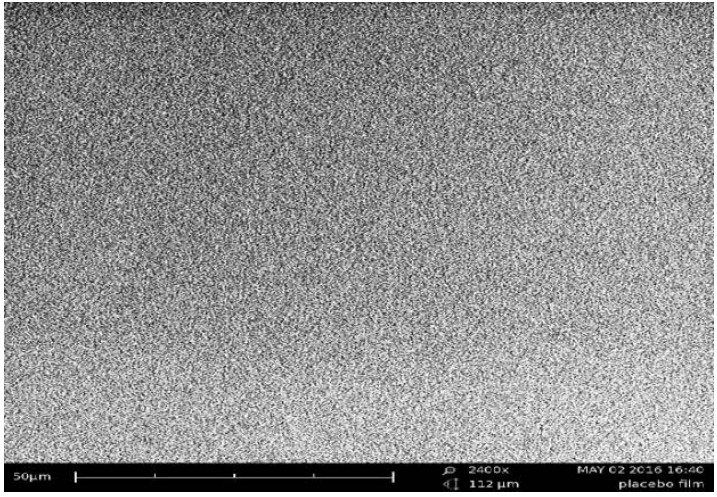

Fig. 3: Scanning electron microphotograph of the placebo sublingual film without the addition of fentanyl citrate microemulsion

\section{Ex vivo permeation study}

Permeation studies through goat sublingual mucosa indicated that the \% cumulative release of fentanyl citrate from FC C2 ME sublingual film (F3) was $89 \%$ and plain FC sublingual film was $40 \%$, respectively. This indicates that the extent of permeation of fentanyl citrate from F3 was around 2.225 folds higher than that of plain fentanyl citrate sublingual film (Fig.4.). Steady-state flux (Js, $\mu \mathrm{gcm}$ ${ }^{2} \mathrm{~h}^{-1}$ ) was calculated and found $35.286 \mu \mathrm{gcm}^{-2} \mathrm{~h}^{-1}$ for FC C2 ME sublingual film (F3) and $17.242 \mu \mathrm{gcm}^{-2} \mathrm{~h}^{-1}$ for plain fentanyl citrate sublingual film. This evidenced an enhanced permeation of FC when incorporated in microemulsion form in the sublingual film than over plain fentanyl citrate sublingual film.

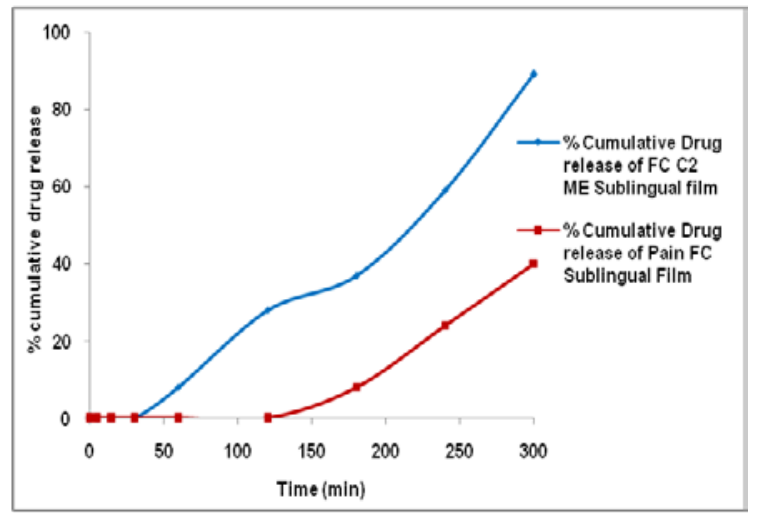

Fig. 4: Ex vivo release profile of fentanyl citrate through FC C2 ME sublingual film (F3) and plain fentanyl citrate sublingual film

\section{Droplet size and polydispersity index (PDI)}

Droplet size of optimized F3 (FC C2) microemulsion obtained after re-dispersion of the sublingual film was $123.5 \mathrm{~nm}$ and PDI was 0.313 , which confirmed narrow size distribution of oil droplets (fig. 5.) $[39,40]$. The increased particle size of FC C2 microemulsion after re-dispersion from sublingual film was maybe due to covering of the embedded microemulsion with polymeric matrix of sublingual film.

\section{Zeta potential measurements}

Zeta potential of microemulsion present in optimized FC C2 ME sublingual film (F3) obtained after re-dispersion of the film was 13.1 $\mathrm{mV}$. Despite the low ZP value, the system remains stable [41]. The graph of intensity (a. u.) vs ZP (mV) of C2 ME obtained after redispersion from the sublingual film was exhibited in the fig. 6 . 


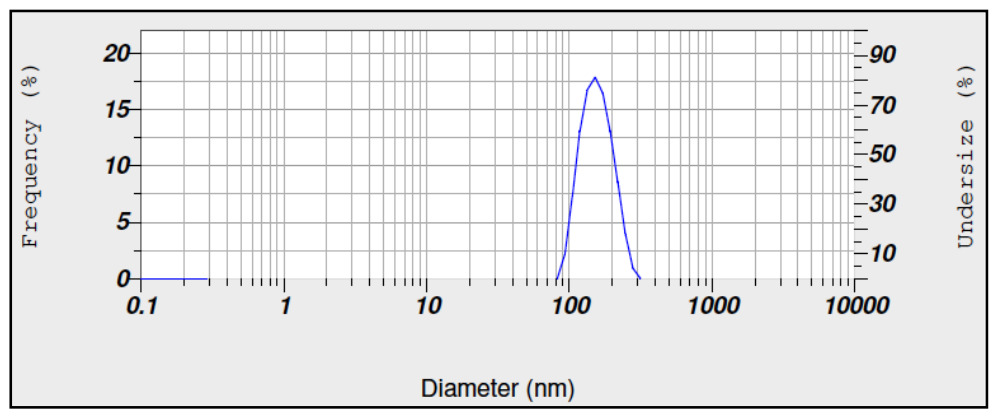

Fig. 5: Particle size distribution plot of optimized F3 (FC C2 ME) sublingual film

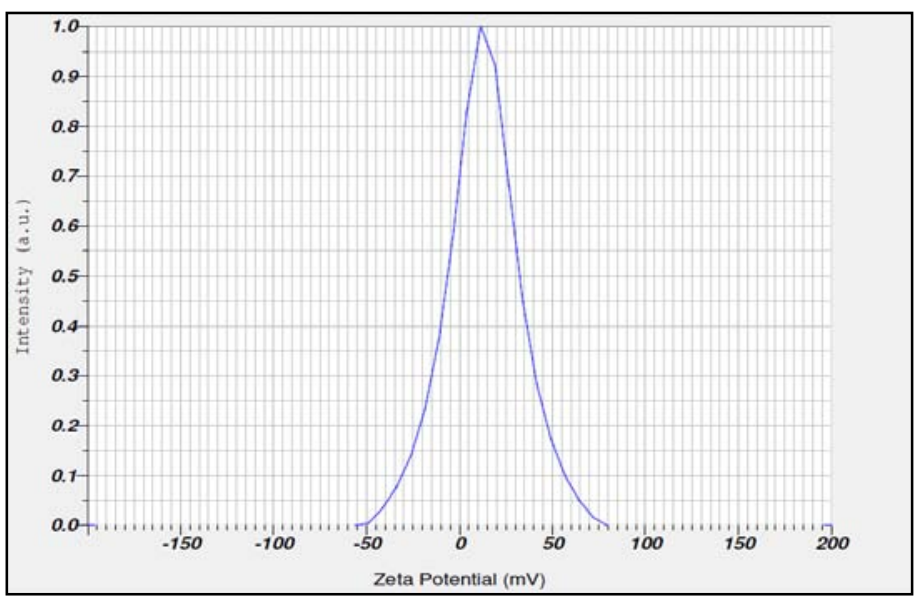

Fig. 6: Zeta potential plot of optimized F3 (FC C2 ME) sublingual film

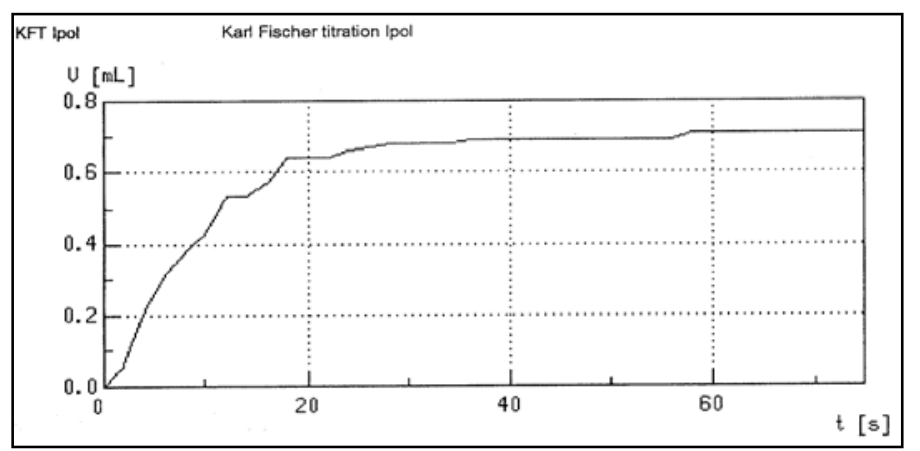

Fig. 7: Karl fischer titration curve for optimized F3 (FC C2 ME) sublingual film

\section{$\%$ Moisture content (Karl Fisher titration method)}

The water content of the optimized F3 (FC C2 ME) sublingual film was found to be $3.67 \%$ and its Karl Fischer titration curve graph was shown in fig. 7.

\section{Stability study}

The stability study of film formulations was carried out at room condition and at $40^{\circ} \mathrm{C} / 75 \% \mathrm{RH}$ for a period of one month. No change was observed in the appearance and flexibility of film. The drug content and surface $\mathrm{pH}$ was found to be almost constant for up to one month.

\section{ACKNOWLEDGEMENT}

The authors are thankful to Centre for Advanced Research and Innovation (CARIn), Zim Laboratories, Kalmeshwar Dist. Nagpur (M. S.), India, for providing the instrumentation and facilities and License for working with Narcotic opioid analgesic drugs. The authors are sincerely thankful to the Government of India, Ministry of Science and Technology, Department of Science and Technology (DST), New Delhi for their thorough support. The authors are also thankful for our analytical research developmental laboratory team members for providing timely help.

\section{CONCLUSION}

Two processes, namely, preparation of fentanyl citrate microemulsion and their incorporation in sublingual film formulation was integrated successfully. SEM studies revealed that spherical o/w microemulsion droplets of fentanyl citrate were incorporated in the polymeric matrix of sublingual film. It can be revealed from in vitro dissolution and ex vivo permeation studies through goat sublingual mucosa that FC microemulsion-incorporated sublingual film has enhanced the release rate of drug over the plain fentanyl citrate sublingual film. Hence, the present study concludes that the fast-acting fentanyl citrate microemulsion-incorporated sublingual film is a promising alternative to conventional drug delivery systems and a traditional route of administration for breakthrough pain management. 


\section{FUNDING}

Nil

\section{AUTHORS CONTRIBUTIONS}

All authors have contributed equally.

\section{CONFLICTS OF INTERESTS}

The authors report no conflicts of interest.

\section{REFERENCES}

1. Roy SD, Flynn GL. Solubility and related physicochemical properties of narcotic analgesics. Pharm Res 1988;5:580-6.

2. Gardner Nix J. Oral transmucosal fentanyl and sufentanil for incident pain. J Pain Symptom Manage 2001;22:627-30.

3. McMillan C. Breakthrough pain: assessment and management in cancer patients. Br J Nurs 2001;10:860-6.

4. Portenoy RK, Hagen NA. Breakthrough pain: definition, prevalence and characteristics. Pain 1990;41:273-81.

5. Zeppetella G. Sublingual fentanyl citrate for cancer-related breakthrough pain: a pilot study. Palliat Med 2001;15:323-8.

6. Zhang H, Zhang J, Streisand JB. Oral mucosal drug delivery: clinical pharmacokinetics and therapeutic applications. Clin Pharmacokinet 2002;41:661-80.

7. Ozdemir V, Kalow W, Tang BK, Paterson AD, Walker SE, Endrenyi L. Evaluation of the genetic component of variability in CYP3A4 activity: a repeated drug administration method. Pharmacogenetics 2000;10:373-88.

8. Labroo RB, Paine MF, Thummel KE, Kharasch ED. Fentanyl metabolism by human hepatic and intestinal cytrochrome P450 3A4: implication for interindividual variability in disposition efficacy and drug interactions. Drug Metab Dispos 1997;25:1072-80.

9. Allan L, Hays H, Jensen NH, De Waroux BL, Bolt M, Donald R. Randomised crossover trial of transdermal fentanyl and sustained-release oral morphine for treating chronic noncancer pain. Br Med J 2001;322:1154-8.

10. Gourlay GK. Treatment of cancer pain with transdermal fentanyl. Lancet Oncol 2001;2:165-72.

11. Mather LE, Woodhouse A, Ward ME, Stephen J, Farr JS, Rubsamen AR. Pulmonary administration of aerosolised fentanyl: pharmacokinetic analysis of systemic delivery. Br J Clin Pharmacol 1998;46:37-43.

12. Coyne PJ, Viswanathan R, Smith TJ. Nebulized fentanyl citrate improves patients' perception of breathing, respiratory rate, and oxygen saturation in dyspnea. J Pain Symptom Manage 2002;23:157-60.

13. Blick SKA, Wagstaff AJ. Fentanyl buccal tablets in breakthrough pain in opioid-tolerant patients with cancer. Drugs 2006;66:2387-93.

14. Vasisht N, Gever LN, Tagarro I, Finn AL. Single-dose pharmacokinetics of fentanyl buccal soluble film. Pain Med 2010;11:1017-23.

15. Darwish M, Kirby M, Robertson P, Tracewell W, Jiang JG. Absolute and relative bioavailability of fentanyl buccal tablet and oral transmucosal fentanyl citrate. J Clin Pharmacol 2007;47:343-50.

16. Stanley TH, Hague B, Mock DL, Streisand JB, Bubbers S, Dzelzkalns RR. Oral transmucosal fentanyl citrate (lollipop) premedication in human volunteers. Anesth Anal 1989;69:21-7.

17. Christie J, Simmonds M, Patt R, Coluzzi P, Busch MA, Nordbrock E. Dose-titration multicenter study of transmucosal fentanyl citrate for the treatment of breakthrough pain in cancer patients using transdermal fentanyl for persistent pain. J Clin Oncol 1998;16:3238-45.

18. Streisand JB, Varvel JR, Stanski DR, Le Maire L, Ashburn MA, Hague BI. Absorption and bioavailability of oral transmucosal fentanyl citrate. Anesthesiology 1991;75:223-9.

19. Portenoy RK, Payne R, Coluzzi P, Raschko JW, Lyss A, Busch MA. Oral transmucosal fentanyl citrate (OTFC) for the treatment of breakthrough pain in cancer patients: a controlled dose titration study. Pain 1999;79:303-12.
20. Lim SCB, Paech M, Sunderland VB, Roberts M, Banks S, Rucklidge M. Pharmacokinetics of nasal fentanyl. J Pharm Prac Res 2003;33:59-63.

21. Mercadante S, Radbruck L, Davies A, Poulain P, Sitte T, Perkins P. A comparison of intranasal fentanyl spray with oral transmucosal fentanyl citrate for the treatment of breakthrough cancer pain: an open-label, randomized, crossover trial. Curr Med Res Opin 2009;25:2805-15.

22. Kaasa S, Moksnes K, Nolte T, Lefebvre Kuntz D, Popper L, Kress HG. Pharmacokinetics of intranasal fentanyl spray in patients with cancer and breakthrough pain. J Opioid Manage 2010;6:17-26.

23. Weinberg DS, Inturrisi CE, Reidenberg B, Moulin DE, Nip TJ, Wallenstein S. Sublingual absorption of selected opioid analgesics. Clin Pharmacol Ther 1988;44:335-42.

24. Bredenberg S, Duberg M, Lennernas B, Lennernas H, Pettersson A, Westerberg M. In vitro and in vivo evaluation of a new sublingual tablet system for rapid oromucosal absorption using fentanyl citrate as the active substance. Euro J Pharm Sci 2003;20:327-34.

25. Lennernas B, Frank Lissbrant I, Lennernas H, Kalkner KM, Derrick $\mathrm{R}$, Howell J. Sublingual administration of fentanyl to cancer patients is an effective treatment for breakthrough pain: results from a randomized phase II study. Palliat Med 2010;24:286-93.

26. Zeppetella G. Sublingual fentanyl citrate for cancer-related breakthrough pain: a pilot study. Palliat Med 2001;15:323-8.

27. Jangipuria F, Londhe V. Solubility enhancement of lurasidone hydrochloride by preparing SMEDDS. Int J Pharm Pharm Sci 2015;7:283-8.

28. Mauludin R, Mohamad SF, Suciati T. Formulation and characterization of ascorbyl palmitate loaded $\mathrm{o} / \mathrm{w}$ microemulsion. Int J Pharm Pharm Sci 2014;6:294-8.

29. Tiwari RR, Umashankar MS, Damodharan N. Recent update on oral films: a bench to market potential. Int J Appl Pharm 2018;10: 27-33

30. Nafee NA, Boraie NA, Ismail FA, Mortada LM. Design and characterization of mucoadhesive buccal patches containing cetylpyridinium chloride. Acta Pharm 2003;53:199-212.

31. Gould K, Desai H, Kumar TMP. Preparation and evaluation of novel buccal adhesive system. AAPS PharmSciTech 2004;5:1-9.

32. Irfan M, Rabel S, Bukhtar Q, Qadir MI, Jabeen F, Khan A. Orally disintegrating films: a modern expansion in drug delivery system. Saudi Pharm J 2015;24:537-46.

33. Fentanyl citrate Injection. United States Pharmacopoeia 30 National Formulary 25 (USP-NF) The Official Compendia of Standards United States Pharmacopeial Convention; 2014.

34. United States Food and Drug Administration (US FDA) Fentanyl citrate Dissolution Database. Available from: https://www.accessdata.fda.gov> Drug Databases > Dissolution Methods [Last accessed on 21 Apr 2017]

35. Kumar GP, Phani AR, Prasad RG, Sanganal JS, Manali N, Gupta R. Polyvinylpyrrolidone oral films of enrofloxacin: Film characterization and drug release. Int J Pharm 2014;471:146-52.

36. Kaur G, Singh D, Brar V. Bioadhesive okra polymer-based buccal patches as a platform for controlled drug delivery. Int J Biol Macromol 2014;70:408-19.

37. Govindasamy P, Kesavan BR, Narasimha JK. Formulation of unidirectional release buccal patches of carbamazepine and study of permeation through porcine buccal mucosa. Asian Pac J Trop Biomed 2013;3:995-1002.

38. Darwish MK, Elmeshad AN. Buccal mucoadhesive tablets of flurbiprofen: characterization and optimization. Drug Discovery Ther 2009;3:181-9.

39. Nidhin M, Indumathy R, Sreeram KJ. Synthesis of iron oxide nanoparticles of narrow size distribution on polysaccharide templates. Bull Material Sci 2008;31:93-6.

40. Kumar R, Sinha VR. Preparation and optimization of vornicazole microemulsion for ocular delivery. Colloids Surfaces B 2014;117:82-8.

41. Quaglia F, Ostacolo L, Mazzaglia A, Villari V, Zaccaria D, Sciortino MT. The intracellular effect of non-ionic amphiphilic cyclodextrin nanoparticles in the delivery of anticancer drugs. Biomaterials 2009;30:374-82. 